\title{
Freud, LeAr \& BloOM: algumas nOtAS \\ SOBRE LEITURA E PSICANÁLISE
}

Guilherme Gutman

(FREUD, Sigmund. "O motivo da escolha do cofre". Em: Obras Completas. Buenos Aires: Amorrortu, 1913/1993, v. XII:303-17.)

- (FREUD, Sigmund. "Carta 409 F". Em: Sigmund Freud \& Sándor Ferenczi: correspondência. Rio de Janeiro: Imago, 1913/1995: 226.)

•(FREUD, 1913/1993: 307.)

\section{Freud leitor de Lear}

Em uma carta de Junho de 1912 a Ferenczi, Freud antecipa àquele que era, então, um de seus discípulos mais próximos, as principais conclusões a que chegara para O Motivo da Escolha do Cofre. ${ }^{*}$ Decorrido pouco mais de um ano, em outra carta, Freud faz ao mesmo Ferenczi uma pequena confidência:

Sabe que, este ano, não convidei os Emden[s], por mais amável que seja a sua companhia, para ter algumas semanas em Marienbad, liberado de análises. Minha relação mais próxima será minha filha menor, ${ }^{1}$ que agora se desenvolve tão a contento (há muito que o Sr. deve ter adivinhado esta condição subjetiva da "escolha do cofre")."

No texto de 1913, referido nas duas cartas, Freud aborda "duas cenas de Shakespeare, uma divertida e, a outra, trágica", sendo a primeira de O Mercador de Veneza e a segunda de Rei Lear. Com a confiança e a aplicação que lhe eram habituais, Freud afirma ter recebido das cenas "a ocasião para colocar-[se] um pequeno problema e resolvê-lo”. *

A primeira das cenas é assim apresentada por ele:

A (cena) alegre é a escolha dos pretendentes entre três cofres em $O$ mercador de Veneza. A bela e prudente Porcia é obrigada, por vontade de seu pai, a tomar por esposo, entre os seus cortejadores, somente o que escolhesse o correto de três cofrezinhos que lhe fossem apresentados. Um era de ouro, outro de prata e o terceiro de chumbo; o correto era aquele que encerrasse o seu retrato. Já haviam fracassado dois cortejadores, que escolheram ouro e prata. Bassânio, o terceiro, se decide pelo chumbo; ganha assim a noiva, de quem já possuía a simpatia mesmo antes da prova do destino.*

\footnotetext{
${ }^{1}$ Trata-se de Anna Freud, a caçula dos seis filhos de Freud e, afinal, a terceira de três filhas. (GAY, Peter. Freud: uma vida para nosso tempo. São Paulo: Companhia das Letras, 1989.) Na clássica biografia de Freud escrita por Jones lê-se na dedicatória: "To Anna Freud: true daughter of an immortal sire." (JONES, Ernest. The Life and Work of Sigmund Freud (abridged). New York, Anchor: 1963.) Neste uso, "true" pode ter o sentido mais comum de "verdadeira", mas também de "sincera" ou de "leal". As diferentes traduções para "true" encontrarão uma inquietante ressonância nas possibilidades de tradução da mesma palavra em uma determinada fala de Cordélia em Rei Lear, como se verá adiante.
} 
Ao se prosseguir na leitura do texto, notamos Freud apressando-se em revelar que o tema da decisão entre os cofres não é invenção de Shakespeare, mas que foi tomado de uma fonte conhecida: a Gesta Romanorum. É possível dar continuidade à busca de Freud por referências, e elaborar um pequeno inventário de possíveis fontes ou, pelo menos, de outras criações nas quais também se presentifica o tema em questão. Como exemplo, por Heliodora, fica-se sabendo que:

A trama de $O$ mercador de Veneza [é dotada] de fortes características de narrativas tradicionais como os contos de fadas ou os do folclore. Uma escolha a ser feita entre três opçōes, duas erradas e uma certa - e que tanto podem ser objetos quanto pessoas - tem sido apresentada em incontáveis manifestaçōes com toda espécie de variantes, como por exemplo $O$ amor de três laranjas, Cinderela ${ }^{2}$ ou as três irmãs do Rei Lear, mas a quase totalidade do enredo tal como ele se apresenta nesta comédia, Shakespeare o encontrou na história de Gianetto em uma coletânea de novelle italianas intitulada Il Pecorone, que foi escrita - ou talvez apenas organizada - por Ser Giovanni Fiorentino, escritor de quem não se conhece qualquer outra obra. Nessa fonte, no entanto, a prova para a conquista da moça é apresentada sob a forma de o candidato agüentar uma noite inteira acordado, sendo que os dois primeiros são adormecidos com soníferos ministrados às escondidas; a variante com três arcas, ${ }^{3}$ por outro lado, o poeta pode ter tirado do poema Confessio Amantis, de John Gower, do Decameron, de Boccaccio, ou da veneranda Gesta Romanorum, que nasceu no século XIV mas teve duas ediçōes em inglês no século XVI.

Notificar e resenhar as fontes das quais Shakespeare teria se servido - mitos, contos, lendas, relatos, criaçōes poéticas - faz notar que há temas que se colocam, de forma mais ou menos permanente, à disposição de quem quer que se disponha a recolhê-los. Mas há uma diferença fundamental entre, de um lado, notar a ubiqüidade de determinado motivo e, de outro, ser tocado subjetivamente, como o foi Freud, por sua presença na pena do homem de Stratford-upon-Avon.

Vale, portanto, notar que o interesse de Freud pelas cenas referidas não foi (pelo menos não em um primeiro momento) um interesse teórico, mas algum outro menos racionalizado. Em ou-

\footnotetext{
${ }^{2}$ Freud, na primeira das referidas cartas a Ferenczi, cogita a presença do tema em Cinderela (FREUD, Sigmund. "Carta 307 F”. Em: Sigmund Freud \& Sándor Ferenczi: correspondência. Rio de Janeiro: Imago, 1912/1995: 10..)

${ }^{3}$ Como se nota, Heliodora, tradutora de $O$ mercador de Veneza, prefere verter "casket", do original em inglês, (SHAKESPEARE, William. "The Comical History of the Merchant of Venice, or otherwise called the jew of Venice". Em: The Complete Works. Oxford: Oxford, 1986a: 479-508.) por "arca" a "cofre".
}

"(HELIODORA, Barbara. “O mercador de Veneza (introdução)". Em: SHAKESPEARE, William. O mercador de Veneza. Rio de Janeiro: Nova Fronteira, 1990: 134.) 
tras palavras, ao notar ter sido afetado pelo que leu, saiu, por assim dizer, em busca das razões de sua comoção. Mais que isso, procurou entender as razóes para a força notável presente nas cenas, em especial por saber que Shakespeare, antes de falar a Freud, fala a muitos. A experiência de ler Shakespeare pode implicar no encontro de algo que parecerá bastante íntimo, mas que é, em essência, material de acesso público.

$\mathrm{Na}$ construção de sua interpretação para a cena de $O$ mercador de Veneza, e depois, como se verá, para a cena de Rei Lear, Freud percorrerá os locais nos quais se repete o tema da eleição forçosa entre três possibilidades ofertadas. Neste caminho, encontra determinados mitos, para os quais o epíteto "originários", caso fosse aplicado, não teria um sentido rigoroso. É que para Freud a mitologia não é necessariamente campo matriz de nossas crenças e pensamentos, sendo mais apropriadamente descrita como um sedimento de invenções bem terrenas. Sobre isso, ele escreve:

Nós não acreditamos, ao contrário de muitos mitólogos, que os mitos tenham caído do céu; julgamos (...) que foram projetados no céu depois de terem nascido em outra parte, sob circunstâncias puramente humanas. E bem, a esse conteúdo humano se dirige o nosso interesse.

Conjeturando que a escolha do personagem Bassânio entre os três cofres representa um tema de valor universal, qual seja, " $a$ escolha que um homem faz entre três mulheres", Freud apresenta a segunda e trágica cena:

Este mesmo é o conteúdo de outra cena de Shakespeare, em um de seus dramas mais comoventes; não se trata dessa vez de eleger uma noiva, apesar de que muitíssimas afinidades secretas enlaçam esta cena com a escolha dos cofrezinhos em $O$ mercador de Veneza. O velho rei Lear decide repartir, em vida, o seu reino entre as suas três filhas segundo a medida do amor que elas lhe demonstrem. As duas maiores, Goneril e Regan se desmancham em juras e louvores de seu amor; em oposição, à terceira, Cordélia, que se recusa a fazê-lo. Ele deveria ter sido capaz de reconhecer este amor recatado, sem palavras, da terceira, e recompensá-lo; mas se equivoca quanto a ela, a repudia e reparte o reino entre as outras duas, para o seu próprio infortúnio e para o infortúnio de todos. Não é também esta uma eleição entre três mulheres, dentre as quais a mais jovem é a melhor, a perfeita?*

Mesmo um estudo biográfico superficial de Freud tornaria grande a tentação de passagem ao ato patográfico, porque, a partir dele, não seria difícil identificar Anna a Cordélia e Freud a Lear; 
mas para o presente trabalho basta saber, e neste sentido a correspondência entre ele e Ferenczi nos foi útil, que o próprio Freud insinua as conexões entre ele, a sua filha e os citados personagens de Shakespeare. O entrelaçamento dos motivos e dos conflitos estará na base de qualquer interpretação de filiação psicanalítica.

Em um esforço de alinhavar o que foi referido até aqui, somado à tentativa de esboço de alguns tópicos a serem desenvolvidos, temos que:

a) Algo presente em Rei Lear toca Freud, estimulando-o, intimando-o, empurrando-o, enfim, em direção ao trabalho de análise do drama.

b) Ao analisar o texto, Freud se depara com um tema que julga universal, e que nota disponível desde sempre; portanto, disponível aos que antecederam Shakespeare e aos que o sucedem, entre eles, o próprio Freud. Há, em síntese, algo que sempre esteve lá, à disposição de quem possa ser tocado por esse algo. E Shakespeare, alinhando magnificamente forma e conteúdo, ocupa, de algum modo, o centro canônico das "aparições" do tema que, nesse contexto, poderia ser chamado de causa dos efeitos subjetivos que eventualmente provoca.

c) Considerando que esse algo a que nos referimos comove Freud, imediatamente reconhecemos nele a mesma substância daquilo que, tal qual se postulou, sempre esteve aí. Como coadunar tal idéia com aquela outra, presente em Freud, segundo a qual aquilo que se encontra em um mito é na verdade um reencontro, uma vez que originalmente extrato "humano" e só posteriormente "projetado no céu"? Ao colocar as produções psíquicas de extrato inconsciente no centro da cena, é como se Freud dissesse: aquilo que está "lá"; aquilo a respeito do qual temos notícia por Shakespeare, antes de estar lá esteve "aqui" (sendo este "aqui" alguma localidade psíquica). Nesta acepção, Freud ofereceria um modelo circular, de acordo com o qual teríamos projetado, em algum momento primevo, determinados núcleos de conflito psíquico sobre personagens literários; num segundo momento, reencontraríamos estes mesmos núcleos plasmados em literatura; e, finalmente, após um trabalho analítico sobre os deslocamentos e condensações produzidos pelos mecanismos defensivos, retornaríamos, dos temas literários, aos conflitos psíquicos originais.

d) Ao apontar razões subjetivas para seu interesse pelo motivo da escolha entre três, Freud reconhece a sua filiação ao, digamos, 
material dramático. Mas se, com Lacan, nos propusermos a rever o modelo circular apresentado no item acima, encontraremos uma mudança de perspectiva quanto à internalidade dos assim chamados conflitos psíquicos. Não há razóes para se discordar de Freud no que diz respeito ao fato de que os temas de Shakespeare sempre estiveram lá, à disposição, como já foi formulado. Também não há porque se opor à idéia de que estes já foram conteúdos psíquicos, mas (e essa é a mudança de perspectiva) "externo" e "interno", nesse caso, coincidem: motivos inconscientes são, naturalmente, experienciados como "nossos motivos", portanto, como experiências mentais internalizadas. Mas embora as experiências sejam (segundo um certo modelo de aparelho psíquico) indubitavelmente internas, os motivos não estão "dentro de nós", e sim em toda parte - literatura, folclore, mitologia - e desde sempre. Pela expressão "nossos conteúdos psíquicos" devemos entender partes desse "algo que está aî", que experimentamos (e com um sabor inquestionável de verdade histórica individual) como alguma coisa que definitivamente nos diz respeito. Sem dar uma resposta final à questão, pode-se dizer, com Freud, que somos lá onde não nos sabemos, e que, sobretudo pelas evidências presentes na repetição sintomática de modos de ser, de sentir e de pensar, somos todos capazes de notar os efeitos de constituição subjetiva, desse "lá" sobre nós. Ler freudianamente um texto literário é, sobretudo, não esquecer-se disso.

\section{Freud crítico de Lear}

O método de Freud para a análise crítica do tema da "escolha entre três", em especial do julgamento feito por Lear sobre as diferenças de intensidade do suposto amor de suas três filhas por ele, tem como ponto absoluto de origem (e de retorno) a percepção de que há algo em cena que é dele, Freud. Seu método começa, portanto, na firmeza com que abraça tal percepção e, também, no esforço de não afastar-se dela, ou pelo menos no compromisso ético de não negar a determinação inconsciente de seu interesse pela cena dramática.

Mas que pistas se pode ter, afinal, do interesse de Freud por Lear?

Ele é similar a qualquer especial interesse que se tenha por um livro, e é da mesma ordem que aquela eventual e surpreendente experiência, comum a todos, que é permanência (e insistência) na memória de uma dada situação, literária ou não. $\mathrm{O}$ retorno per- 
sistente do texto de um determinado personagem é análogo, por exemplo, à ruminação de uma idéia, ou à presença de um afeto para o qual não temos ainda um nome; é, enfim, um sintoma como qualquer outro. Sintoma lato sensu, é certo; porque neste caso não é exatamente um indicativo de psicopatologia. Antes, é um modo de lidar com "um algo" que ainda não encontrou as palavras que a tornariam outra coisa que não esse algo vivo, inquieto e indestrutível que tem a capacidade (ainda que a preço de sofrimento psíquico) de se fazer notar. Encontradas, tais palavras irão desfazer, modificar ou moderar a repetição sintomática e imperativa dos modos provisórios de gerência dos efeitos sobre o eu, desse algo que se expressa ultrapassando o sujeito.

Na psicanálise, muitas vezes tudo o que se deseja é a substituição de um sintoma por outro. Não há a expectativa de que se conclua o processo de uma análise sem sintomas, porque não é possível, afinal, viver sem algum elemento que faça a articulação dos imperativos pulsionais à cadeia inconsciente, isto é, o simbólico.

Freud toma para si a cena da tragédia, como quem se debruça sobre um sonho, ou sobre qualquer outra formação do inconsciente, que poderiam ser seus. Sabe que há ali coisas, embora expressas segundo regras muito diferentes daquelas que caracterizam o discurso coerente e bem elaborado da consciência, em relação às quais deve assumir alguma responsabilidade. Passa então a uma espécie de caminho de volta - talvez um percurso mais de construção do que de desvelamento - no qual parte do conteúdo manifesto, em direção ao "imprevisto e inconcebível" que pode ser chamado conteúdo oculto.

Neste processo, Freud se fixará sobre determinadas palavras - chumbo, mutismo, palidez - que surgem com uma qualidade perceptiva que as diferencia daquelas que compóem o resto do texto, e em relação às primeiras, como na interpretação de sonhos, ${ }^{*}$ ele se permitirá algumas associaçōes:

[As particularidades] da terceira mulher, a superior (...) parecem tender a alguma unidade (...). Cordélia não se faz notar, é modesta como o chumbo, permanece muda, ela "ama e silencia". (...) Resolvemos comparar o chumbo a Cordélia, obstinada em sua negativa. E do chumbo, diz Bassânio em seu breve discurso durante a escolha dos cofres, de modo realmente intempestivo:

"Tua palidez (paleness) ${ }^{4}$ me inspira mais do que a eloqüência."

\footnotetext{
${ }^{4}$ Freud aponta, em uma nota de rodapé, que, em outra versão de Rei Lear, aparece em substituição a paleness, plainness, palavra para a qual ele adota como tradução "simplicidade".
}

"(FREUD, Sigmund. "Recordar, Repetir y Reelaborar (Nuevos consejos sobre la técnica del psicoanálisis, II)". Em: Obras Completas. Buenos Aires: Amorrortu, 1914/1993, v. XII: 145-57.)

*(FREUD, Sigmund. "La Interpretación de los sueños". Em Obras Completas. Buenos Aires: Amorrortu, 1900/1994, v. IV \& V: 1-611.) 
-(FREUD, 1913/1993: 30910 , grifos nossos.)

(FREUD, 1900/1994.)

(FREUD, 1913/1993.)
Equivale a dizer: tua simplicidade me satisfaz mais do que a natureza estridente das outras duas. Ouro e prata são "sonoros"; o chumbo é mudo, exatamente como Cordélia, que "ama e silencia”. (...)

Se nos decidimos por ver concentradas as peculiaridades de nossa terceira no "mutismo", a psicanálise nos diz: mutismo é nos sonhos uma figuração usual da morte.

Como entender a expressão "a psicanálise nos diz", acima empregada por Freud?

Em primeiro lugar, como uma ratificação da idéia de que a palavra, a lembrança ou a imagem que aparece no discurso deverá sempre remeter a outras palavras, e que de "pensamentos intermediários" se chegará a algo que, por força da repressão, não pôde ser falado."

Em segundo, que todas as associações "intermediárias" não possuem o mesmo teor de verdade que os "pensamentos inconscientes”, mas que, ao contrário, são desvios ou transformaçōes destas.

Terceiro, que as transformações que sofrem os ditos elementos originários seguem regras específicas. Cada associação que surge articula-se a outras palavras, que irão compondo uma cadeia na qual cada elemento que a compõe só ganha sentido quando referido a outros.

Enfim, que entre o discurso homogêneo e bem montado da consciência e os significantes do inconsciente há uma distância significativa; que o discurso consciente é, aqui e ali, perturbado pelas premências do inconsciente, sob a forma de sonhos, de atos falhos, de chistes, e que, às vezes, há palavras cuja presença parece remeter mais diretamente a algo que não é da série dos escamoteamentos da consciência, mas da materialidade significante.

É na série chumbo-palidez-mutismo que Freud identifica algo dessa espécie. Não deixa escapar esse fio e, atrás dele, vai mais uma vez em direção a algo que, definitivamente, não está explícito sob as formas habituais do discurso. Ao contrário, como no contexto clínico de um processo analítico, isso que temos insistido em chamar de "algo" só aparece quando, após um longo percurso de repetição narrativa, ele resta como segmento vivo da linguagem no centro do terreno desbastado das palavras gastas.

Se, como diz Freud, "a terceira das irmãs (...) seria uma morta, mas também pode ser outra coisa, a saber: a própria morte", " cabe entâo perguntar sobre o que poderia levar alguém a escolher a morte.

Em $O$ mercador de Veneza [a terceira irmã] é a mais formosa e prudente das mulheres, em Rei Lear é a única filha fiel. Pode conceberse uma contradição mais completa? Não obstante, talvez devamos observar assim mesmo essa grande e inverossímil contradição. E em verdade ela existe, pois em nosso tema, escolhendo-se livremente en- 
tre três mulheres, a escolha sempre recai sobre a morte; e ninguém esco-

the a morte, de quem se é vitima por fatalidade.

"(Idem: 314, grifos nossos.)

É preciso notar aqui a marca diferencial do método psicanalítico, que faz de uma aparente contradição - e, nesse contexto, "aparente" tem o sentido duplo daquilo que apenas na superfície aparenta ser contraditório porque de modo algum é contraditório ${ }^{*}$ - a enunciação de uma verdade. Isto porque, numa primeira etapa de elaboração do conteúdo manifesto do tema em questão, o ponto não é tanto o que se escolhe (isto é, o objeto da escolha), mas sim a possibilidade de escolher, em oposição aos desígnios naturais da morte. Num primeiro momento, o que se deseja é ter direito a uma escolha, ainda que essa escolha recaia sobre a morte. Num segundo momento, nota-se que, se a escolha recai sempre sobre a morte, é porque se trata, no âmbito do desejo, da inversão da ordem natural das coisas: onde antes era "a morte escolhe", passa-se a "escolho a morte".

Sobre esse "desarranjo do desejo", e sobre a oposição entre os conteúdos aparente e originário, diz Freud:

A escolha ocupa o lugar da necessidade, da fatalidade. Assim, o homem vence a morte, a quem teria reconhecido em pensamento. Não se concebe maior triunfo de cumprimento do desejo. Escolhe-se ali onde a realidade efetiva obedece à compulsão, e não se escolhe a terrível, senão a mais bela e desejável (como ocorre em $O$ mercador de Veneza e em Rei Lear).

E, se observamos melhor, notamos que as desfigurações do mito originário não são tão radicais a ponto de não denunciá-lo por uns fenômenos residuais. A livre escolha entre as três irmãs não é na verdade livre, pois deve recair necessariamente sobre a terceira, sob pena de engendrar, como em Rei Lear, toda classe de infortúnios..$^{5^{*}}$

Todavia, como ainda se verá na última seção do presente artigo, a inversão da "realidade efetiva" não esgota as complexidades do desejo que, de natureza inconsciente, não deixa de retornar e de produzir efeitos que marcam a superfície do psiquismo. Há algo do desejo na experiência da "escolha da morte"; mas há algo do desejo também na escolha por essa meta específica - a finitude.

\section{Freud, Lear e Bloom}

Como foi visto na seções anteriores, Freud é captado por algo presente nas cenas de $O$ mercador de Veneza e de Rei Lear, em especial o tema da escolha entre três mulheres. Além disso, ele atribui

\footnotetext{
${ }^{5} \mathrm{O}$ mesmo vale para $O$ mercador de Veneza, posto que a escolha de Bassânio pelo cofre errado, isto é, pelos cofres de ouro ou prata, também implicaria em tragédia.
} 
parte da força de Shakespeare à capacidade de recuperar o sentido originário de determinada composição mitológica, sob os véus das desfigurações perpetradas pelos mecanismos defensivos do eu. É assim, por exemplo, que a escolha de Bassânio pelo cofre de chumbo é, numa interpretação que faz deslizar o sentido do chumbo por palidez e mutismo, a escolha pela morte. O desejo de escolha pela morte é o sentido originário das cenas; é aquela peça do inconsciente que sempre esteve lá, exercendo pressão sobre a vida consciente, fazendo-se notar nos lapsos da língua, nos sintomas ou, simplesmente, naquela palavra que surge acompanhada de uma qualidade da experiência que autoriza a distingui-la da massa homogênea do discurso consciente.

Mas Freud faz notar que Shakespeare não é o único escritor capaz de facilitar a seus leitores o caminho em direção ao inconsciente, sendo esta uma característica comum aos grandes da literatura e até mesmo, o que não deixa de ser desconcertante, a alguns nem tão grandes assim. Se isto é verdade, o que faz de Shakespeare um autor diferente, por exemplo, dos irmãos Grimm, também citados por Freud em $O$ motivo da escolha do cofre? Para esse efeito de remeter o leitor a temas míticos e universais, diferença alguma. Volta e meia somos provocados, ou mesmo atingidos com fúria, por textos que jamais receberiam de crítico literário algum a avaliação de boa literatura. Se há diferença, ela diz respeito a uma característica distintiva de alguns personagens de Shakespeare: a capacidade de reflexão, isto é, a capacidade de, ao longo da história da qual fazem parte, irem dizendo-se coisas; isto é, dizendo algo deles, por eles e para eles mesmos. Haveria em Shakespeare essa rara junção da capacidade de colocar o leitor frente àquilo que retorna, que insiste no discurso, na boca de personagens que, num movimento autoreflexivo, tomam gradativamente consciência do que são.

Unindo as duas pontas do mesmo fio, notamos, na leitura que Freud faz do Lear, que se Shakespeare reduz a desfiguração da qual o mito originário teria sido objeto, é porque ele sopra no ouvido do leitor o sentido do sintoma no qual era enovelado aquilo que não se podia dizer. Shakespeare, se lido plenamente, faz escutar o que insiste em retornar; Freud, por sua vez, revela toda a espessura dessa possibilidade viva, que é a de escutar a si próprio e fixar-se sobre a palavra emitida.

Esta idéia - a de que ao lermos Shakespeare estaremos diante de personagens auto-reflexivos - é explorada às últimas consequiências 
pelo crítico literário Harold Bloom. Ao construir uma teoria do jogo de influências entre autores "fortes", Bloom* desenvolve (e radicaliza) as idéias de que Freud teria sido o inventor de nossas formas de autoreflexão subjetiva e a de que, posto que Shakespeare teria "inventado" Freud, ${ }^{6}$ no limite Shakespeare teria inventado o humano.

Sobre as relaçôes entre os personagens de Shakespeare e a capacidade de "entreouvir-se" - essa que, entre outras, parece destacar-se como aquela qualidade que mais identificamos à idéia de "profundidade psíquica” -, Bloom disserta:

Antes de Shakespeare, os personagens literários são, relativamente, imutáveis. Homens e mulheres são representados, envelhecendo e morrendo, mas não se desenvolvem a partir de alteraçóes interiores, e sim em decorrência de seu relacionamento com os deuses. Em Shakespeare, os personagens não se revelam, mas se desenvolvem, e o fazem porque têm a capacidade de se auto-recriarem. Às vezes, isso ocorre porque, involuntariamente, escutam a própria voz, falando consigo mesmos ou com terceiros. Para tais personagens, escutar a si mesmos constitui o nobre caminho da individuação."

Se, no que diz respeito a Shakespeare e a Freud, decidirmos deixar de lado a polêmica e acompanhar Bloom em parte de seu percurso sinuoso, descobriremos que ele oferece um instrumento analítico interessantíssimo que permite, entre outras coisas, extrair conseqüências máximas da idéia de que uma das coisas mais ricas que um personagem literário tem a oferecer aos que ainda lêem de modo voraz e veraz, como dizia Barthes, é a sua capacidade de se fazer ouvir e, no mesmo movimento, ensinar-nos a ouvirmos a nós mesmos. Nesse sentido, um autor forte não faz mais do que um convite a que experimentemos a dobra da dobra: curvando-nos sobre nós mesmos, experimentamos o eco em voz familiar de uma palavra emitida outrora.

Neste ponto, caberia a pergunta sobre se a leitura plena de Shakespeare equivaleria, em seus efeitos, à experiência de uma aná-

\footnotetext{
${ }^{6}$ Exemplos da posição adotada por Bloom estão em diversas passagens, como: "Para Freud, (...) as obras de Shakespeare eram o centro secular da cultura (...). Em algum nível, ele entendia que Shakespeare inventara a psicanálise, ao inventar a psique, até onde Freud podia reconhecê-la e descrevê-la" (BLOOM, Harold. $O$ cânone ocidental: os livros e a escola do tempo. Rio de Janeiro: Objetiva, 1995a: 65); ou "Durante muitos anos, ensinei que Freud é essencialmente Shakespeare prosificado: a visão da psicologia humana de Freud deriva, não de todo inconscientemente, de sua leitura das peças" (ibid: 358); ou ainda "A menos que se seja um religioso freudiano, essa é a antiga história da influência literária e suas ansiedades. Shakespeare é o inventor da psicanálise; Freud, seu codificador" (ibid: 361).
}

* (BLOOM, Harold. A angústia da influência: uma teoria da poesia. Rio de Janeiro: Imago, 1991a; Cabala e crí tica. Rio de Janeiro: Imago 1991b; Poesia e repressão: o revisionismo de Blake a Stevens. Rio de Janeiro: Imago 1992; Um mapa da desleitura. Rio de Janeiro: Imago, 1995b.)

(BLOOM, Harold. Shakespeare: a invenção do humano. Rio de Janeiro: Objetiva, 2000: 19.) 
lise clínica. Para uma resposta segura, não é preciso mais do que o dado empírico de quem experimenta ambas: são definitivamente experiências distintas que conduzem o sujeito por caminhos também distintos e, enfim, não levam aos mesmos lugares. Mas seria difícil dizer qual das experiências está aquém ou além da outra, do mesmo modo que seria fácil dizer que talvez sejam experiências complementares - na teoria, como tantas vezes o comprovou Freud, enriquecem-se mutuamente. No que diz respeito à clínica psicanalítica propriamente, porque poderia servir como uma peça que do lado do psicanalista funcionasse como chave de acesso a determinadas formaçôes subjetivas; do lado do analisando, por sua vez, poderia modular a experiência de análise para quem por ela é atravessado.

Então, o que ganhamos ao lermos determinados autores com Freud?

Em primeiro lugar, aprendemos a criar uma determinada expectativa em relação aos personagens literários fortes.

Em segundo lugar, passamos a ter direito a essa mesma expectativa, que se soma a uma outra, a saber, aquela que acompanha as ações de se assistir, especular, interpretar e, enfim, esperar o tempo do personagem na construção de um diálogo com ele mesmo e na chegada a algum ponto no qual também somos atingidos.

\section{Lear leitor de Freud}

Ao se perguntar sobre as razōes da força presente em Rei Lear, Freud recusa, ao menos enquanto explicação única, as causas mais comumente aludidas pela crítica. Ele admite, por exemplo, que há em Lear, entre os seus temas fortes, "a tragédia da ingratidão, cuja ferida talvez [Shakespeare] tenha sentido em sua própria carne”. Exatamente aí nos perguntamos se Freud já não passa a falar dele mesmo e, portanto, de algo que, por sentir na própria pele, condiciona a sua interpretação da peça. Perguntamo-nos também se, ao apontar aquilo que estaria na base do impacto universal desta obra de Shakespeare, não estaria novamente Freud trabalhando sob os efeitos provocados pela tragédia. Escreve ele:

Lear é um homem velho. (...) Lear é não só um velho, como um moribundo. (...) Mas esse condenado à morte não quer renunciar ao amor da mulher, ${ }^{7}$ quer ouvir que lhe digam o quanto é amado. Considere-se agora a mobilizadora cena final, um dos pontos mais

\footnotetext{
${ }^{7}$ De acordo com Freud, amor dirigido à mulher impessoal, deslocado à filha,
} Cordélia. 
altos do trágico dentro do drama moderno: Lear carrega o cadáver de Cordélia pelo palco. Cordélia é a morte. Se a invertemos, ${ }^{8}$ a situação se torna inteligível e familiar. É a deusa da morte quem leva o herói morto do campo de batalha, como as Valquírias na mitologia alemã. A sabedoria eterna, com a roupagem do mito primordial, aconselha o anciāo a renunciar ao amor, a escolher a morte e a reconciliar-se com a necessidade de fenecer.

Nessa perspectiva, o efeito dramático do Lear é dado por um personagem que vai dizendo a si mesmo que morre e que, afinal, é preciso que seja assim: nem excepcional, nem fora do mundo, nem mais nem menos amado do que quem já esteve vivo.

A análise feita por Bloom, em contrapartida, difere frontalmente daquela construída por Freud. De acordo com o crítico,

Freud, aos cinqüenta e sete anos, ainda tinha vinte e seis a viver, mas não podia falar do "herói" sem se colocar no papel. Renunciar ao amor, preferir a morte e fazer as pazes com a necessidade de morrer é coisa de Hamlet, mas não combina com o Rei Lear. Os reis demoraram a morrer, em Shakespeare e na vida, e Lear é a maior de todas as representaçôes de um rei. (...) Seu principal defeito em relação a Cordélia é um amor excessivo, que exige excesso em troca. (...) Lear (...) não pode sobreviver a Cordélia. *

Quem estará mais certo em sua interpretação da comoção vivida por Lear? Não parece determinante, nesse caso, tomar partido nem de Freud nem de Bloom, porque é possível supor que ambos constroem as suas interpretaçôes tomando parte no jogo ou, em outras palavras, colocando algo que é deles na cena. Também não é preciso partir em direção à desgastada tentativa de demonstração patográfica do que é de Freud e do que é de Bloom nas respectivas interpretações. Se um texto é capaz de representar um psiquismo ou se, ao contrário, algum psiquismo pode representar um texto, é só porque "cada um deles é um afastamento do significado propriamente dito”. *

De qualquer modo, não há dúvida de que, lento ou rápido, Lear caminha para a morte. Conhecemos Lear, "com mais de oitenta anos, (...) cansado" e desejando "rastejar sem cargas para a morte". A esta altura da vida, como aponta Heliodora, Lear já fazia a sua "longa e dolorosa caminhada de rei a homem" . Portanto, era alguém que, pela primeira vez, se deparava com algo que era ainda maior do que

\footnotetext{
${ }^{8}$ Essa “inversão" poderá, a leitor não tão familiarizado com a clínica psicanalítica, parecer um tanto aleatória, não fosse o fato de que, como foi visto na segunda seção desse trabalho, as formações do inconsciente freqüentemente surjam invertidas em seu conteúdo manifesto.
}

•(FREUD, 1913/1993: 316-7, grifos nossos.)

"(BLOOM, 1995a: 71-3, grifos nossos.)

"(BLOOM, 1992: 13.)

"(HELIODORA, Barbara. Falando de Shakespeare. São Paulo: Perspectiva, 1998: 173.)

"(Idem: 174.) 
(FREUD, Sigmund. "Além do princípio do prazer". Em: Escritos sobre a psicologia do inconsciente. Rio de Janeiro: Imago, 1920/2006, v. II: 162.)

Palavras-chave: psicanálise; crítica literária; Freud; Shakespeare; Harold Bloom.

Key words: psychoanalysis; literary criticism; Freud; Shakespeare; Harold Bloom.

Mots-clés: psychanalyse, critique littéraire, Freud, Shakespeare, Harold Bloom

Recebido em 16/03/2008

Aprovado em 15/04/2008

a sua realeza. E se pudermos reunir, nem que apenas por um momento, as interpretações de Freud e de Bloom, veremos então que se há em Lear alguma recusa, hesitação ou postergação quanto ao momento de morrer, é só porque, como em um desejo incompleto, não encontra a morte do modo como a ansiou em vida.

Freud, sete anos após ter publicado $O$ motivo da escolha do cofre, modifica enormemente a sua teoria pulsional - pilar fundamental de sua metapsicologia - ao introduzir o conceito de "pulsão de morte". É em Além do princípio do prazer que ele afirma que, se todos desejam enfim retornar ao estado inorgânico no qual cessam inteiramente todas as inquietações que são parte indissociável da vida, tudo que um homem pode desejar é, em última instância, "morrer à sua maneira".

Lear não pôde sobreviver a Cordélia. Sendo assim, sua tragédia foi a de caminhar para a morte com o peso de um corpo que não era o seu.

\section{Guilherme Gutman}

Psicanalista e psiquiatra, doutor em saúde coletiva pelo Instituto de Medicina Social - UERJ, professor do Departamento de Psicologia da PUC-Rio.

\section{Resumo}

Permanência dos temas à disposição do escritor; entrelaçamento de temas e de conflitos na compreensão psicanalítica do humano; externalidade do inconsciente; interpretação como construção; valor da literatura na clínica psicanalítica; Lear e a finitude.

\section{Abstract}

Permanency of motifs available to the writer; interweaving of motifs and conflicts in the psychoanalytical understanding of the human being; externality of the subconscious; interpretation as a form of construction; the importance of literature in clinical psychoanalysis; Lear and finitude.

\section{Résumé}

Permanence des thèmes à la disposition de l'écrivain; entrelacement des thèmes et des conflits dans la compréhension psychanalytique de l'humain; externalité de l'inconscient; interprétation comme construction; l'importance de la littérature dans la psychanalyse clinique; Lear et la finitude. 